\title{
Levels of Resistance in ribosomes from Genetically Linked, Streptomycin-resistant Mutants of Pneumococcus
}

\author{
By J. J. STUART AND A. W. RAVIN \\ Department of Biochemistry, School of Medicine and Dentistry, and Department \\ of Biology, University of Rochester, Rochester, New York, U.S.A.
}

(Accepted for publication 24 October 1967)

\begin{abstract}
SUMMARY
A streptomycin-sensitive strain and six streptomycin-resistant mutants of pneumococcus have been studied. These strains differed in resistance to streptomycin over a 5000-fold range, and the resistance mutations occurred at recombinationally distinct sites of a single genetic locus (the str locus). The effects of streptomycin on cell-free amino acid incorporating systems prepared from each of the strains were studied. Both polyuridylic acid (poly U)- and endogenous mRNA-directed systems were employed. As in Escherichia coli, sensitivity to streptomycin was found to reside in the ribosomal fraction of the amino acid incorporating system.

Streptomycin caused both inhibition of ${ }^{14} \mathrm{C}$-phenylalanine incorporation and stimulation of ${ }^{3} \mathrm{H}$-isoleucine incorporation in poly U-directed experiments. The resistance of the amino acid incorporating systems to these effects of streptomycin paralleled the streptomycin resistance of the strain from which the system was derived. In endogenous mRNA-directed systems the incorporation of ${ }^{14} \mathrm{C}$-valine and ${ }^{3} \mathrm{H}$-isoleucine was followed simultaneously. Streptomycin caused an inhibition of valine incorporation and a lesser inhibition of isoleucine incorporation. At a higher magnesium concentration streptomycin caused a stimulation of isoleucine incorporation while still inhibiting valine incorporation. The disparate behaviour of isoleucine and valine incorporation in the presence of streptomycin may be due to streptomycin-induced misreading of endogenous mRNA. As in the poly U-directed experiments, the magnitude of the effects of streptomycin on endogenous mRNA directed amino acid incorporation correlated in an inverse fashion with the resistance of the strain from which the system was prepared.

These results lead us to conclude that the ribosome is the primary target for streptomycin in pneumococcus. We propose that the affinity of the ribosome for streptomycin at a critical site or sites determines the level of resistance of the bacterium, and that this affinity is affected by mutations in the str locus.
\end{abstract}

\section{INTRODUCTION}

In Escherichia coli mutations to streptomycin (SM) resistance and dependence are closely linked (Newcombe \& Nyholm, I950). Rotheim \& Ravin (I96I, I964) and Mishra \& Ravin (I966) showed that this is true as well in pneumococcus. By means of transformation analysis a large number of streptomycin resistance mutations was mapped in this organism. Although these mutations varied greatly in phenotype, raising the level of resistance of the pneumococcus by as little as tenfold to as much as several thousand fold, they were all found to occupy sites within a single genetic 
locus. Mutations conferring relatively low levels of resistance were usually interrecombinable, while mutations conferring high levels of resistance replaced the lowlevel resistance mutations rather than combining with them.

Several workers (Flaks, Cox, Witting \& White, I962; Speyer, Lengyel \& Basilio, 1962; Davies, 1964; van Knippenberg et al. 1965) have shown that a mutation to streptomycin resistance in Escherichia coli is associated with an alteration in the ribosomes, so that ribosomes isolated from resistant cells are comparatively resistant to the stimulatory, inhibitory, and misreading effects of streptomycin in vitro. Streptomycin resistance in $E$. coli is not always associated, however, with resistant ribosomes. Rosenkranz (1964) has described a streptomycin-resistant $E$. coli strain in which the resistance was due to the presence of a multiple-drug-resistance episome. In this case the cell apparently became impermeable to, or destroyed the antibiotic while the ribosomes remained sensitive.

The purpose of the present investigation was to determine whether the ribosomes of the previously mapped pneumococcal mutants were resistant to streptomycin, and if they were to compare the level of resistance of the ribosomes to the level of resistance of the cells from which the ribosomes had been isolated. Ribosomal resistance was studied in vitro by determining the levels of streptomycin which were necessary to cause inhibition of amino acid incorporation and misreading in cell-free systems prepared from each of the mutants. Both poly U- and endogenous mRNA-directed cell-free systems were studied.

\section{METHODS}

Materials. L-valine-1-14C and DL-phenylalanine-1-14C were obtained from New England Nuclear Corp., Boston, Mass. In addition, some of the valine used was synthesized by Dr Leon Miller of the University of Rochester. L-isoleucine- ${ }^{3} \mathrm{H}$ was obtained from Schwarz BioResearch, Inc., Orangeburg, N.Y. ATP and phosphocreatine were purchased from Sigma, St Louis, Mo. Mercaptoethanol and GTP were obtained from Calbiochem, Los Angeles, Cal.; Escherichia coli B sRNA (stripped) came from General Biochemicals, Chagrin Falls, Ohio; and poly U was purchased from Miles Chemical Co., Elkhart, Ind. Streptomycin sulphate was purchased from Eli Lilly and Co. Erythromycin lactobionate was obtained from Abbott Laboratories and chlortetracycline from Lederle Laboratories.

Strains. The strains used and the maximum amounts of streptomycin which they can withstand in vivo without significant loss of colony-forming ability are as follows: SIII-I (sensitive, about $2 \mu \mathrm{g} . / \mathrm{ml}$.); str-r 42 (30 $\mu \mathrm{g} . / \mathrm{ml}$.); str-r 3 (I $50 \mu \mathrm{g} . / \mathrm{ml}$.); str-r 48 (I50 $\mu \mathrm{g} . / \mathrm{ml}$.); str-r $2(300 \mu \mathrm{g} . / \mathrm{ml}$.); str-r I $(5000 \mu \mathrm{g} . / \mathrm{ml}$.$) ; and s t r-r 5 I$ (between I0,000 and $15,000 \mu \mathrm{g} . / \mathrm{ml}$.). Streptomycin kills at concentrations exceeding those listed for the respective strains, the rate of killing being dependent upon the concentration of antibiotic. The origins and genetic relationships among these strains have previously been reported (Rotheim \& Ravin, I96I, I964); the most recent genetic map is contained in Mishra \& Ravin (1966).

Growth of organisms. The media and procedure for growing pneumococcus have previously been described (Ephrussi-Taylor, I95I; Rotheim \& Ravin, I96I). The cocci were harvested after $75 \mathrm{ml}$. of $\mathrm{N}-\mathrm{NaOH}$ (necessary for the neutralization of the acid produced by the growing cells) had been added to a 31 . volume of a growing culture. At this point the cell density, determined by viability count, was about $\mathrm{I} \times \mathrm{IO}^{9}$ 
cocci $/ \mathrm{ml}$. Six litres of culture yielded 9-I I g. of wet cocci. The harvested cocci could be frozen or used immediately for the preparation of a cell-free extract.

Cell-free extract $(S-30)$. Cell-free extracts were prepared essentially according to the method of Matthaei \& Nirenberg (I96I). When it was appropriate, the S-30 extract was further separated into ribosome and S-I0o fractions as described by these authors.

Preincubated $S$-3o ( $S$-30 pre.). When poly U was the messenger, the S-30 was preincubated (Nirenberg \& Matthaei, I96I) in order to minimize incorporation due to the endogenous messenger. S-30 and preincubated S-30 were stored at $-65^{\circ}$ until use.

Amino acid incorporation in cell-free extracts. Endogenous mRNA-directed incorporation was carried out in a volume of $0.5 \mathrm{ml}$. The following were present ( $\mu$ moles/ml.): 100 tris(hydroxymethyl)-aminomethane, $\mathrm{pH} 7.8$ at $37^{\circ} ;$ I00 ammonium acetate, II or I6 magnesium acetate; 6.0 mercaptoethanol; 0.03 each of $20 \mathrm{~L}$-amino acids minus valine; $0.03{ }^{14} \mathrm{C}$-valine (Io $\mu \mathrm{C} / \mu$ mole); $0.03 \mathrm{GTP}, 6.0$ phosphocreatine; $\mathrm{I} \cdot 0 \mathrm{ATP} ; 40 \mu \mathrm{g}$. creatine kinase; from I to $2 \mathrm{mg} . / \mathrm{ml}$. cell-free extract protein. In most experiments the incorporation of ${ }^{3} \mathrm{H}$-isoleucine and ${ }^{14} \mathrm{C}$-valine was followed simultaneously, in which case isoleucine was omitted from the amino acid mixture and $0.03 \mu$ mole ${ }^{3} \mathrm{H}$-L-isoleucine (Ioo $\mu \mathrm{c} / \mu$ mole) was added in its place. Protein was estimated by the method of Lowry, Rosebrough, Farr \& Randall (1956) using a standard solution of bovine serum albumin (Standard Scientific Supply Corp., New York, N.Y.) as a standard. Antibiotics were added where indicated.

The same components were present when poly $U$ was the messenger except that the cold amino acid mixture was omitted and the labelled amino acids present were ${ }^{14} \mathrm{C}$-DL-phenylalanine ( $5 \mu \mathrm{c} / \mu$ mole) and ${ }^{3} \mathrm{H}$-L-isoleucine (Ioo $\left.\mu \mathrm{c} / \mu \mathrm{mole}\right) .300 \mu \mathrm{g} . / \mathrm{ml}$. of Escherichia coli B sRNA (stripped) was added as a supplement. Poly U was present at a concentration of $20 \mu \mathrm{g} . / \mathrm{ml}$. All assays were performed in duplicate or triplicate.

Poly U-directed phenylalanine incorporation did not occur at $37^{\circ}$, but took place when the incubation temperature was lowered to $27^{\circ}$. Our investigations of this temperature effect show that a component of the pneumococcal ribosome can destroy poly $\mathrm{U}$ at $37^{\circ}$ but not at $27^{\circ}$. Because of this effect, poly U-directed reactions were incubated for $2 \mathrm{hr}$ at $27^{\circ}$, at which time they were virtually completed. Amino acid incorporation directed by endogenous mRNA was found to take place at either $27^{\circ}$ or $37^{\circ}$, and since only the rate of incorporation is affected by temperature, the reactions were incubated at the higher temperature. The reactions were completed in $45 \mathrm{~min}$. Experiments were terminated by adding $0.5 \mathrm{ml}$. of $10 \%$ trichloroacetic acid. The protein precipitates were digested at $90-100^{\circ}$ for $\mathrm{I} 5 \mathrm{~min}$., filtered on to discs of Whatman 542 filter paper, and washed with $4 \%$ trichloroacetic acid containing the appropriate cold amino acids at $\mathbf{I} \%$ concentration to reduce the adsorption of the labelled amino acids. The filter discs were counted in a Nuclear Chicago thin-window gas-flow counter, or when it was necessary to count ${ }^{3} \mathrm{H}$ and ${ }^{14} \mathrm{C}$ simultaneously, they were counted in a Packard Tri-Carb Liquid Scintillation Spectrometer. In the latter case NCS Reagent (Nuclear Chicago, Des Plaines, Ill.) (Hansen \& Bush, 1967) was used to dissolve the protein precipitates in a toluene-based scintillation fluid. The efficiency of gas-flow counting for ${ }^{14} \mathrm{C}$ was about $25 \%$. The efficiency of scintillation counting was I I \% for ${ }^{3} \mathrm{H}$ and $50 \%$ for ${ }^{14} \mathrm{C}$. No quenching correction was necessary since the protein precipitates themselves did not quench and NCS Reagent, which did quench, was present in the same concentration in samples and standards. 


\section{RESULTS}

Effect of magnesium ion concentration on poly U-directed phenylalanine and isoleucine incorporation

Many workers have shown in the Escherichia coli system that the concentration of magnesium ion exercises an important influence on the kind and amount of amino acid incorporation (Davies, Gilbert \& Gorini, I964; So, Bodley \& Davie, I964; Szer \& Ochoa, I964; van Knippenberg et al. 1965). Therefore we studied the effect of magnesium concentration on amino acid incorporation into the endogenous mRNAand poly U-directed cell-free system from $S I I I-I$, the sensitive strain.

Figure I shows the incorporation of ${ }^{14} \mathrm{C}$-phenylalanine and ${ }^{3} \mathrm{H}$-isoleucine directed by poly $U$ as a function of the magnesium concentration. The experiment was done both in the absence and in the presence of $1 \cdot 0 \times 10^{-5} \mathrm{M}$-streptomycin. It is evident that in pneumococcus as in Escherichia coli (Davies et al. 1964) streptomycin causes an inhibition of phenylalanine incorporation and a stimulation of isoleucine incorporation. The former appears to be maximal at I I mM-magnesium, while the latter is greatest at I6-2I mM-magnesium. The explanation commonly given for the isoleucine incorporation, which occurs in the presence of streptomycin despite the fact that only the triplet UUU coding for phenylalanine is present, is that streptomycin causes misreading: in its presence the triplet UUU is sometimes read as AUU, which is a codon for isoleucine (Davies, Gorini \& Davis, 1965). In this experiment no isoleucine was incorporated in the absence of streptomycin. In later experiments variable results were obtained so that sometimes a small incorporation of isoleucine was noted even though no antibiotic was present. Davies et al. (I964) have reported similar results with the $E$. coli system.

\section{Effect of magnesium ion concentration on amino acid incorporation directed by endo-} genous $m R N A$

Figure 2 shows the incorporation of ${ }^{14} \mathrm{C}$-valine and ${ }^{3} \mathrm{H}$-isoleucine directed by endogenous mRNA as a function of magnesium concentration. About three times as much valine as isoleucine was incorporated at Io mM-magnesium ion concentration in the absence of streptomycin. When $\mathrm{I} \cdot 0 \times \mathrm{IO}^{-5} \mathrm{M}$-streptomycin was added, the incorporation of both amino acids was inhibited, but not to the same extent, the incorporation of valine being more greatly suppressed than that of isoleucine. In fact, at magnesium concentrations greater than $14 \mathrm{mM}$ streptomycin caused an actual stimulation of isoleucine incorporation.

The magnesium concentration dictated, therefore, whether the incorporation of isoleucine in the endogenous system would be stimulated by streptomycin or partially inhibited, but at all magnesium concentrations the addition of streptomycin resulted in an increase in the ratio of isoleucine to valine incorporated. The increase did not occur, however, if the cell-free system was derived from a highly resistant strain (see Fig. 7 A, B). In a cell-free system derived from a sensitive strain the ratio of isoleucine to valine incorporated was usually about 0.5 and rose to $\mathrm{I} \cdot \mathrm{O}$ or more in the presence of streptomycin. The ratio was not significantly influenced by the time of incubation (Fig. 3) or by the presence of the antibiotics erythromycin (EM) or chlortetracycline (CTC) which, like streptomycin, caused inhibition of phenylalanine incorporation in 


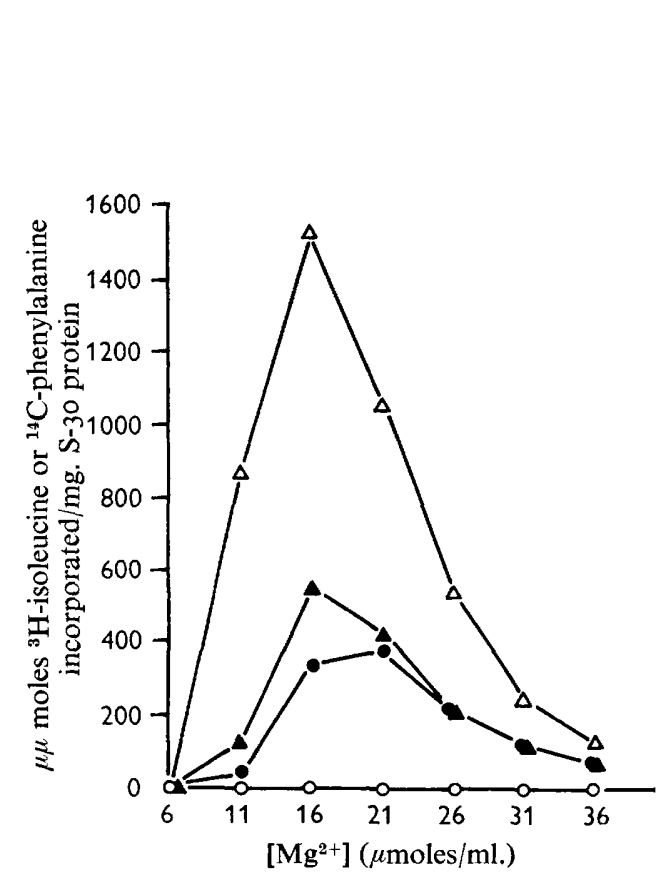

Fig. I

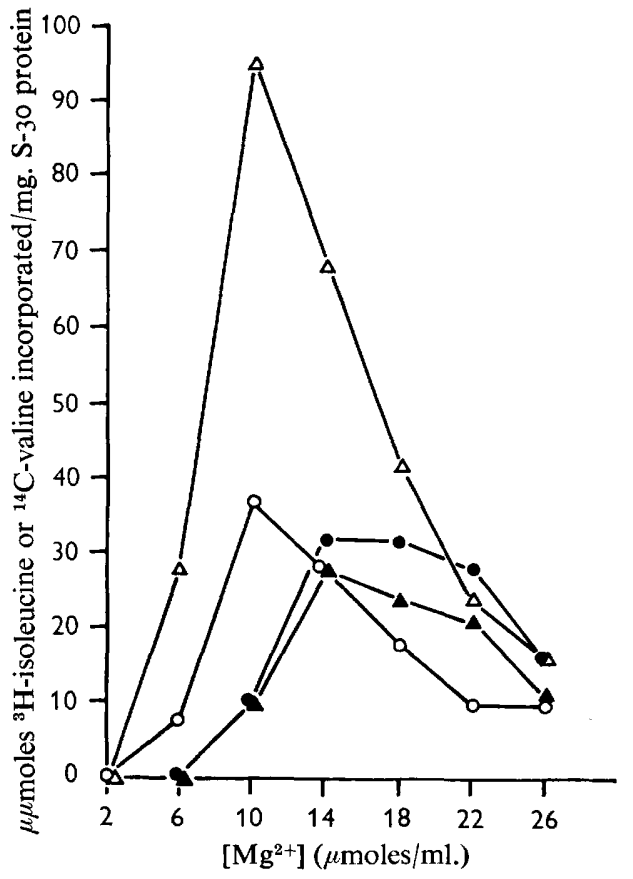

Fig. 2

Fig. I. Incorporation of ${ }^{14} \mathrm{C}$-phenylalanine and ${ }^{3} \mathrm{H}$-isoleucine into $S I I I-I$ S-30 stimulated by poly $U$, in the absence and in the presence of $\mathrm{SM}\left(\mathrm{I} \cdot 0 \times \mathrm{IO}^{-5} \mathrm{M}\right)$ as a function of $\mathrm{Mg}^{2+}$ concentration. Symbols: $\triangle$, phenylalanine in the absence of $\mathrm{SM} ; \boldsymbol{\Delta}$, phenylalanine in the presence of SM; $\mathrm{O}$, isoleucine in the absence of $\mathrm{SM} ; \boldsymbol{O}$, isoleucine in the presence of SM.

Fig. 2. Incorporation of ${ }^{14} \mathrm{C}$-valine and ${ }^{3} \mathrm{H}$-isoleucine into $S I I I-I$ S-30, stimulated by endogenous mRNA in the absence and in the presence of SM $\left(1 \cdot 0 \times 10^{-5} \mathrm{M}\right)$ as a function of $\mathrm{Mg}^{2+}$ concentration. Symbols: $\triangle$, valine in the absence of $\mathrm{SM} ; \boldsymbol{\Delta}$, valine in the presence of $\mathrm{SM} ; \mathrm{O}$, isoleucine in the absence of $\mathrm{SM} ; \mathbf{O}$, isoleucine in the presence of SM.

Table I. Influence of chlortetracycline $(C T C)$, erythromycin $(E M)$, and streptomycin $(S M)$ on the incorporation of ${ }^{14} \mathrm{C}$-phenylalanine and ${ }^{3} \mathrm{H}$-isoleucine into $\mathrm{SIII-I} S$-зo pre. under poly $U$ direction, and on the incorporation of ${ }^{14} \mathrm{C}$-valine and ${ }^{3} \mathrm{H}$-isoleucine into $\mathrm{SIII-I}$ $S$-3o under the direction of endogenous $m R N A$.

The $\mathrm{Mg}^{2+}$ concentration was I I mM in the endogenous mRNA-directed experiments and $16 \mathrm{~mm}$ in the poly $\mathrm{U}$-directed experiments.

Ratio iso-

Isoleu. inc. Valine inc. Phe. inc. leu.:valine

\begin{tabular}{|c|c|c|c|}
\hline Exp & Addition & Messenger* & $\begin{array}{l}\text { ( } \mu \mu \text { moles } / \\
\text { mg. prot. })\end{array}$ \\
\hline
\end{tabular}

$$
\begin{aligned}
& \text { None } \\
& \mathrm{I} \times 10^{-4} \mathrm{M} \mathrm{SM} \\
& \mathrm{I} \times 10^{-5} \mathrm{M} \text { CTC } \\
& \mathrm{I} \times 10^{-4} \mathrm{M} \mathrm{EM} \\
& \text { None } \\
& \mathrm{I} \times 10^{-5} \mathrm{M} \mathrm{SM} \\
& \mathrm{I} \times 10^{-5} \mathrm{M} \text { CTC } \\
& \mathrm{I} \times 10^{-4} \mathrm{M} \mathrm{EM}
\end{aligned}
$$

Poly U
Poly U
Poly U
Poly U
End.
End.
End.
End.

0
I 55
0
4
72
28
3
38

$\begin{array}{rr}- & 414 \\ - & 231 \\ - & 45 \\ -- & 257 \\ 132 & - \\ 26 & - \\ 12 & - \\ 64 & -\end{array}$

0.00

0.67

$0 \cdot 00$

0.02

0.55

$\mathrm{I} \cdot 08$

0.25 0.59

* End. = endogenous mRNA. 
poly-U-directed systems, but did not cause the phenylalanine-isoleucine ambiguity (Table I). The increase in the isoleucine-to-valine ratio appeared therefore to be streptomycin-specific.

\section{Demonstration of ribosomal basis of streptomycin resistance}

In order to determine whether the mutants in our possession, like streptomycinresistant Escherichia coli cells and the streptomycin-resistant pneumococcal mutant reported by Sawada \& Suzuki ( 1964 ), have acquired streptomycin-resistant ribosomes,

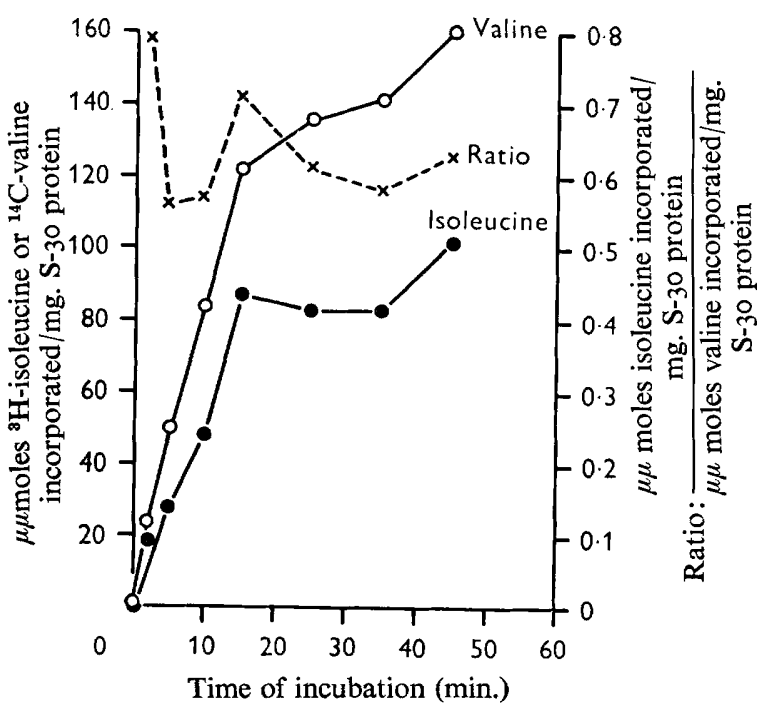

Fig. 3

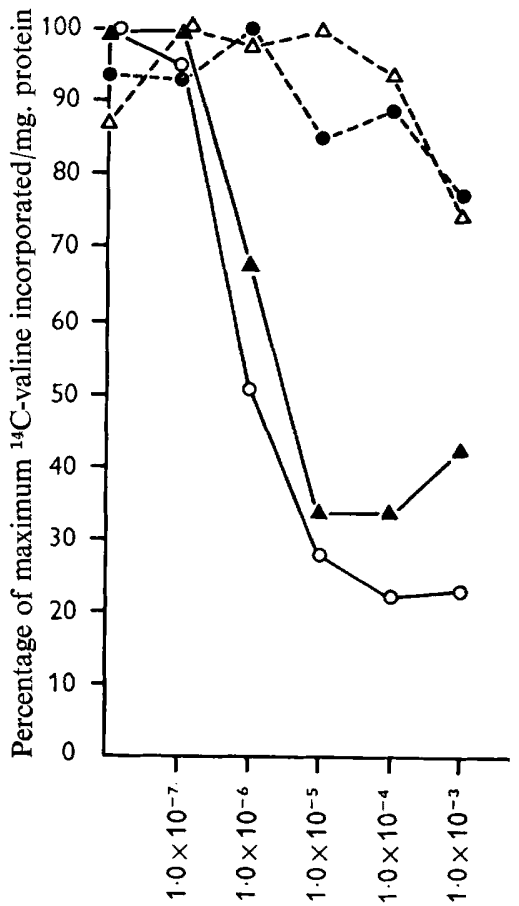

Streptomycin concentration (moles/l.)

Fig. 4

Fig. 3. The endogenous mRNA-directed incorporation of ${ }^{14} \mathrm{C}$-valine and ${ }^{3} \mathrm{H}$-isoleucine into SIII-I S-30 $v$. time. The ratio of $\mu \mu$ moles isoleucine to $\mu \mu$ moles valine incorporated is also plotted. The $\mathrm{Mg}^{2+}$ concentration was I I $\mathrm{mm}$.

Fig. 4. The effect of streptomycin on ${ }^{14} \mathrm{C}$-valine incorporation into ribosomes-plus-S-100 from $S I I I-I$ (sensitive), str-r $5 I$ (resistant), and interchanged ribosomes and supernatant from the two organisms. Symbols: $O, S I I I-I$ ribosomes plus $S I I I-I, S-I 00 ; \triangle$, str-r $5 I$ ribosomes plus str-r $5 I$ S-IOO; $\bullet$, str-r $5 I$ ribosomes plus $S I I I-I$ S-IOO; $\Delta$, SIII-I ribosomes plus str-r $5 \mathrm{I} \mathrm{S}-\mathrm{IOO}$. The $\mathrm{Mg}^{2+}$ concentration in these experiments was $12 \mathrm{mM}$. The incorporation of valine in the absence of SM varied from 90 to $\mathrm{I} 80 \mu \mu \mathrm{moles} / \mathrm{mg}$. protein.

a cross experiment was performed using cell-free extracts from the sensitive $S I I I-I$ and resistant str-r $5 I$ strains. The str-r $5 I$ strain was chosen because the str-r $5 I$ mutation genetically replaces (i.e. is allelic with) all of the other str-r mutations used in this study, and hence any finding concerning the biochemical locus affected by the str-r $5 I$ mutation would be applicable to the other mutations as well. Figure 4 shows that the incorporation of ${ }^{14} \mathrm{C}$-valine directed by endogenous $\mathrm{mRNA}$ is inhibited by strepto- 


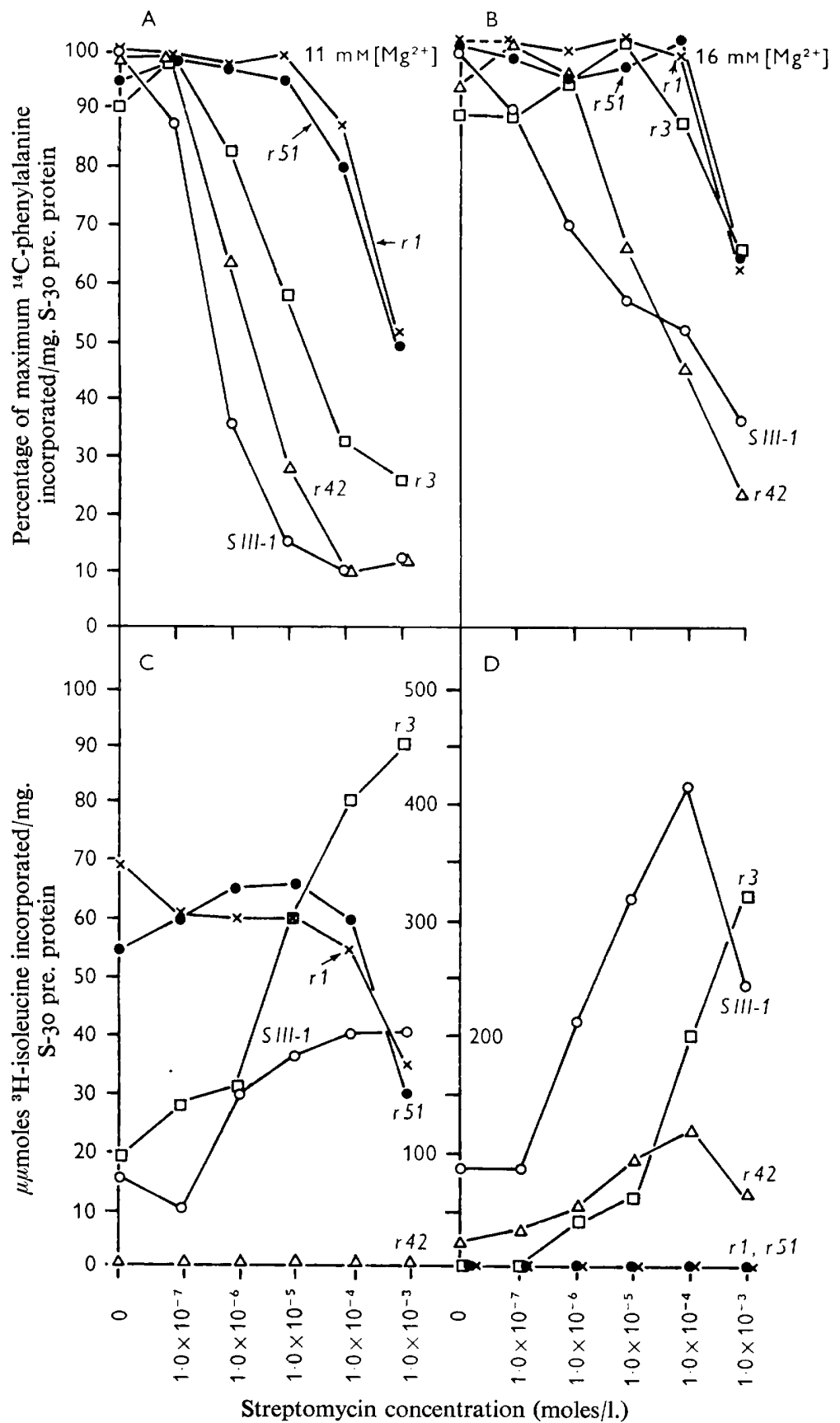

Fig. 5. The effect of SM on the poly U-directed incorporation of ${ }^{14} \mathrm{C}$-phenylalanine and ${ }^{3} \mathrm{H}$-isoleucine into S-30 pre. from a sensitive and four SM-resistant strains of pneumococcus: $A$ and $B$, incorporation of ${ }^{14} \mathrm{C}$-phenylalanine at $\mathrm{II} \mathrm{mm}$ and $\mathrm{I} 6 \mathrm{mM}-\mathrm{Mg}^{2+}$; C and D, incorporation of ${ }^{3} \mathrm{H}$-isoleucine at $\mathrm{I} \mathrm{I} \mathrm{mM}$ and $\mathrm{I} 6 \mathrm{mM}-\mathrm{Mg}^{2+}$. The maximal incorporation of ${ }^{14} \mathrm{C}$-phenylalanine at I I mM- $\mathrm{Mg}^{2+}$ varied from 2000 to $760 \mu \mu \mathrm{mole} / \mathrm{mg}$., depending on the preparation used. At $\mathrm{I} 6 \mathrm{~mm}-\mathrm{Mg}^{2+}$ the maximum incorporation of phenylalanine varied from $\mathrm{I} 860$ to $760 \mu \mu$ mole/mg. 
mycin only when sensitive ribosomes from $S I I I-I$ are present in the incubation mixture. The source of the supernatant has no influence on the results.

\section{Parallelism of in vivo bacterial resistance and in vitro resistance of ribosomes}

It being ascertained that resistant ribosomes were associated with mutations to resistance in vivo, further experiments were performed using mutants making up a spectrum of resistance varying from $30 \mu \mathrm{g} . / \mathrm{ml}$. to slightly over $10,000 \mu \mathrm{g} . / \mathrm{ml}$. of streptomycin. The question to be answered was whether the resistance of the ribosomes of the different mutants to the inhibitory and misreading actions of streptomycin in vitro paralleled the in vivo levels of resistance of the organisms. Both endogenous mRNA- and poly U-directed systems were studied, and experiments were performed at each of two magnesium concentrations, I I $\mathrm{mm}$ and $16 \mathrm{~mm}$, which are near optimal for streptomycin-induced inhibition and misreading respectively. Figure 5 shows the poly U-directed incorporation of phenylalanine and isoleucine into preincubated S-30 (S-30 pre.) prepared from five of the seven pneumococcal strains which are listed in the Methods section. No data are shown for the other two strains, str-r 48 and str-r2. It was found that the ribosomes of str-r 48 could not be distinguished from those of str-r3. Both mutants have the same in vivo streptomycin resistance. Although the amino acid incorporating system from str-r2 was clearly more resistant to streptomycin than that obtained from the sensitive strain, repeated preparations failed to give as active a system as that obtained from all of the other strains we have studied. We suspect that there may be something unusual about the ribosomes of this mutant. Perhaps they are more fragile than those of the other mutants.

At I I mM-magnesium in poly U-directed systems there was a good correlation between the in vivo resistance of the mutant which supplied the ribosomes and the level of resistance of the ribosomes themselves to the inhibition of phenylalanine incorporation by streptomycin (Fig. $5 \mathrm{~A}$ ). SIII-I, str-r42, and str-r 3 could be distinguished from one another and from str-rI and str-r5I. The latter two strains could not, however, be distinguished from one another. These two strains are closer to each other in in vivo level of resistance than are the others.

At II mM magnesium there was no obvious correlation between the quantities of isoleucine incorporated because of misreading and the levels of resistance of the mutants (Fig. $5 \mathrm{C}$ ). In these experiments there was sometimes isoleucine incorporation at a low level in the absence of streptomycin.

When the magnesium ion concentration was raised to $16 \mathrm{~mm}$ (Fig. 5 B,D) the differences among the ribosomes became less distinguishable as far as resistance to streptomycin-caused inhibition of phenylalanine incorporation was concerned, but at the higher magnesium concentration a correlation could be seen between the level of streptomycin needed to stimulate isoleucine incorporation and the level of resistance of the strain from which the ribosomes were taken.

In summary, in poly U-directed systems, at a magnesium concentration favouring inhibition of amino acid incorporation, ribosomal resistance to such inhibition correlated well with the in vivo resistance of the strains. Similarly, at a magnesium concentration favouring misreading (isoleucine incorporation), ribosomal resistance to such misreading was again well correlated with the in vivo levels of resistance.

The findings with endogenous mRNA directed systems at I I and I 6 mM-magnesium were in many ways similar to those obtained with the poly U system. Figure 6 shows 
A

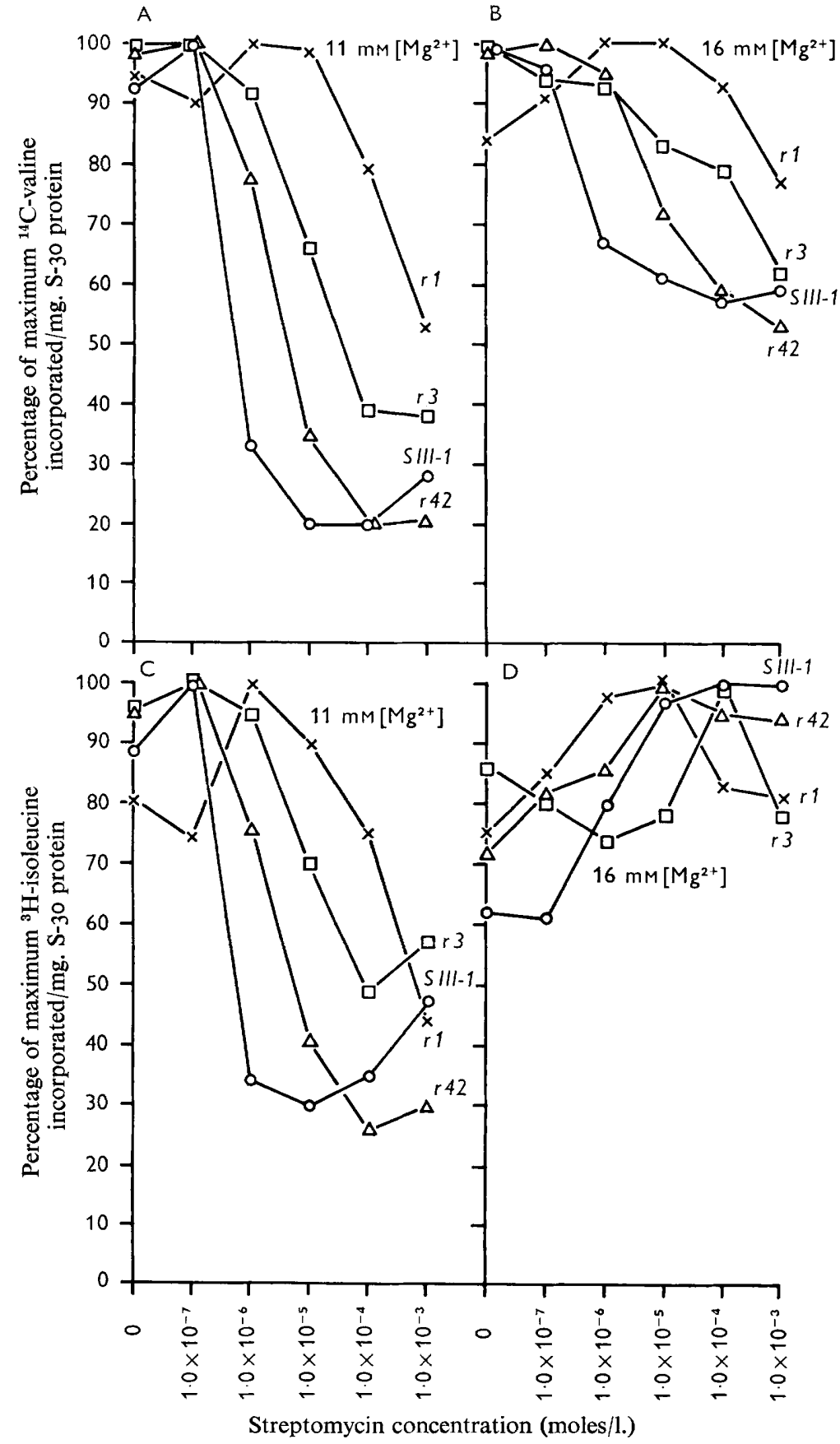

Fig. 6. The effect of SM on the endogenous mRNA-directed incorporation of ${ }^{14} \mathrm{C}$-valine and ${ }^{3} \mathrm{H}$-isoleucine into $\mathrm{S}-30$ from a sensitive and three SM-resistant strains of pneumococcus: $\mathrm{A}$ and $\mathrm{B}$, incorporation of ${ }^{14} \mathrm{C}$-valine at $\mathrm{II} \mathrm{mm}$ and $16 \mathrm{~mm}-\mathrm{Mg}^{2+} ; \mathrm{C}$ and $\mathrm{D}$, incorporation of ${ }^{3} \mathrm{H}$-isoleucine at II $\mathrm{mm}$ and ${ }_{\mathrm{I}} 6 \mathrm{mM}-\mathrm{Mg}^{2+}$. The maximal incorporation of ${ }^{14} \mathrm{C}$-valine at I I mM-Mgen varied from 280 to $120 \mu \mu$ moles $/ \mathrm{mg}$., depending on the preparation used. At $16 \mathrm{~mm}-\mathrm{Mg}^{2+}$ the maximum incorporation of valine varied from 160 to $85 \mu \mu \mathrm{mole} / \mathrm{mg}$. 
these results. The same strains were studied as in the poly $U$ experiments except that str-r $5 I$ was not included because it was not expected that it could be distinguished in any way from $s t r-r I$.

As in the poly $U$ experiments, a correlation was observed between the in vivo resistance of the pneumococcal mutants and the level of resistance of their ribosomes to the inhibitory action of streptomycin on ${ }^{14} \mathrm{C}$-valine incorporation. In the endogenous system this correlation was found at both I I mM (Fig. 6A) and I6 mM-magnesium (Fig. 6B), but the inhibitory action of the antibiotic was less at the higher magnesium concentration. Table 2 shows a detailed comparison between the in vitro resistances of the mutant ribosomes to streptomycin-caused inhibition of valine incorporation at I I mM magnesium and the in vivo resistance of the organisms which supplied the ribosomes. The streptomycin concentration at which half of the maximal inhibition of valine incorporation was achieved was taken as a measure of the in vitro resistance of the ribosomes. It can be seen that between Io and roo times as much streptomycin was needed to prevent a cell from forming a colony as to inhibit amino acid incorporation in a cell-free system derived from the cell.

Table 2. Comparison between the in vitro resistance of ribosomes to inhibition of valine incorporation by $S M$ at II $m M-M g^{2+}$ and the in vivo resistance of the cells which supplied the ribosomes

$\begin{array}{lccc}\text { Streptomycin con- } & \begin{array}{c}\text { Resistance } \\ \text { centration at which } \\ \text { half max. inhibition } \\ \text { achieved (moles/l.) }\end{array} & \begin{array}{c}\text { Resistance } \\ \text { in vitro } \\ \text { of cells } \\ \text { in vivo }\end{array} \\ \text { Strain } & 4 \times 10^{-7} & 0 \cdot 3 & \begin{array}{c}\text { in } / \mathrm{ml} \text {.) } \\ \text { ( } \mu \mathrm{g} \text {. SM } / \mathrm{ml} \text {.) }\end{array} \\ \text { SIII-I } & 3 \times 10^{-6} & 2 & 2 \\ \text { str-r } 42 & 8 \times 10^{-6} & 6 & 30 \\ \text { str-r } 3 & 1 \cdot 3 \times 10^{-4} & 95 & 150 \\ \text { str-r I } & & & 5000\end{array}$

Unlike poly $\mathrm{U}$, endogenous mRNA can be expected to code naturally for isoleucine. Indeed, the incorporation of isoleucine at I I mM-magnesium could be inhibited by streptomycin in much the same fashion as valine in the endogenous system (Fig. 6C). However, the incorporation of isoleucine was not inhibitable to quite the same extent as valine, as noted earlier. This can be seen from Fig. $7 \mathrm{~A}$ and B; here the isoleucine-valine ratio is plotted $v$. streptomycin concentration for the four pneumococcal strains. It is the increase of this ratio with increasing streptomycin concentration which indicates that misreading may be occurring in the translation of the endogenous messenger. The amount of ratio increase which can be caused by the addition of streptomycin is inversely proportional to the in vivo resistance of the strain from which the cell-free system was derived.

At $16 \mathrm{~mm}$-magnesium streptomycin causes an actual stimulation of isoleucine incorporation in all strains (Fig. 6D). In the case of the highly resistant mutant str-rI it is to be noted however, that the stimulation of isoleucine incorporation is accompanied by an equivalent stimulation of valine incorporation (Fig. 6B). Thus the isoleucine-valine ratio remains constant in $s t r-r I$ with increasing streptomycin concentration (Fig. 7 B). A similar stimulatory effect at low streptomycin concentrations on the incorporation of phenylalanine was observed consistently in poly U-directed experiments employing the $s t r-r 3$ cell-free preparation. We do not know the significance of this effect. 


\section{DISCUSSION}

The discovery by Gorini \& Kataja (1964) of Escherichia coli mutants which have a genetic defect suppressible by streptomycin provided the first evidence that the antibiotic can cause the misreading of mRNA. Such misreading has clearly been shown to occur in artificial polynucleotide-directed cell-free systems (Davies et al. 1964; Davies, Jones \& Khorana, I966). Schwartz (1965) has reported that streptomycin causes misreading of the asparagine codon when the RNA of $f_{2}$ bacteriophage is employed as a messenger in an E. coli cell-free system. No evidence has appeared,

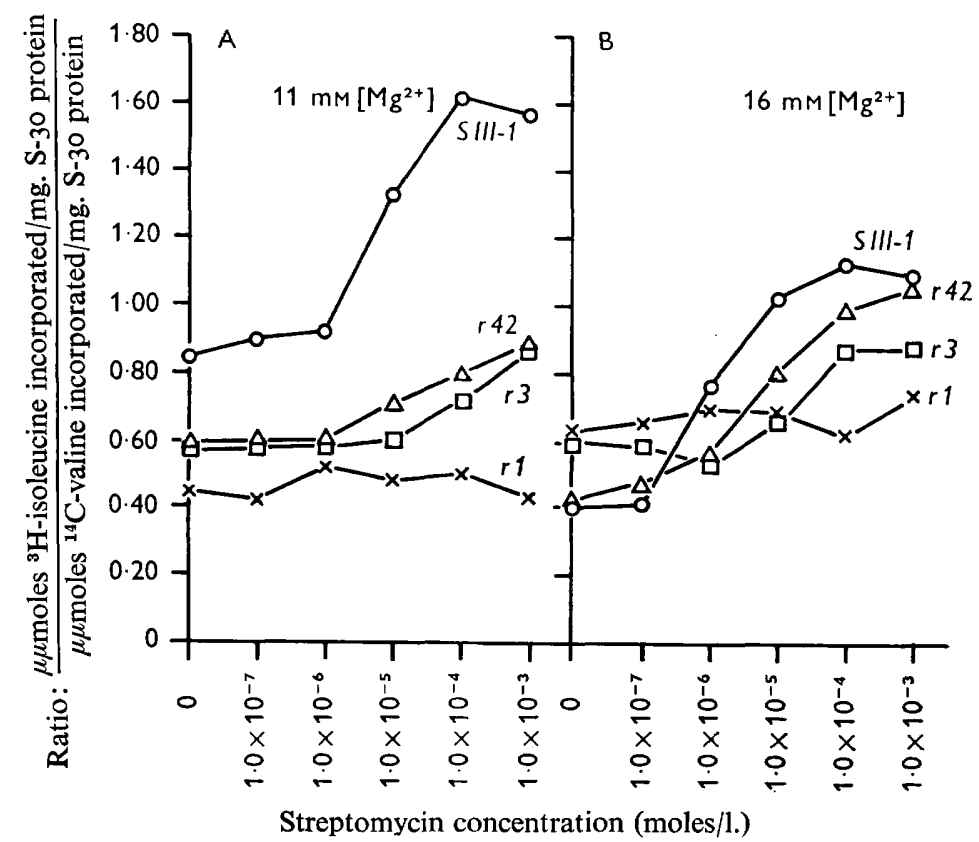

Fig. 7. The effect of SM on the ratio of the amounts of ${ }^{3} \mathrm{H}$-isoleucine and ${ }^{14} \mathrm{C}$-valine incorporated under the direction of endogenous messenger into S-30 from a sensitive and three SM-resistant strains of pneumococcus. Experiments at two different $\mathrm{Mg}^{2+}$ concentrations are shown.

however, which documents the misreading of endogenous mRNA in vitro under the influence of streptomycin. In this regard, our finding that streptomycin causes an increase in the ratio of isoleucine to valine incorporated into cell-free systems prepared from sensitive and low-resistance strains is of interest. The increase in the ratio can be interpreted as the result of the streptomycin-induced misreading of endogenous mRNA. There are two lines of evidence to support this idea. In the first place, the antibiotics erythromycin and chlortetracycline, which inhibit amino acid incorporation without causing misreading of poly $U$, do not bring about any alteration in the ratio of isoleucine to valine incorporated under the direction of endogenous mRNA. Secondly, the isoleucine-valine ratio in endogenous mRNA-directed experiments behaves much like the isoleucine-phenylalanine ratio in poly U-directed experiments. In both cases streptomycin causes an increase in isoleucine incorporation relative to 
that of valine or phenylalanine, and the concentration of streptomycin needed to cause the increase is greater, the greater the resistance of the strain from which the amino acid incorporating system was prepared. In the poly U-directed system the streptomycin-induced increase in isoleucine incorporation can be clearly attributed to the misreading of UUU triplets. While it is not possible to determine which codons are being read in endogenous mRNA, one expects that streptomycin would change the relative amounts of some of the amino acids incorporated in a system directed by endogenous messenger. Interpreted in this light, therefore, the increase in the isoleucine-valine ratio which we observe in the presence of streptomycin could be the result of misreading of the endogenous messenger.

In considering other possible explanations for the ratio increase, the possibility was entertained that a fraction of the isoleucine incorporation was due to the activity of a soluble amino acid incorporating system like that reported by Kaji, Kaji \& Novelli (I965) and that it was resistant to inhibition by streptomycin. This possibility was discarded, however, when we were unable to find evidence that such a system was contributing to the isoleucine incorporation in our experiments.

Spotts \& Stanier (196I) were the first to propose that the ribosome is the primary site of the action of streptomycin. The evidence for this was, and still is, chiefly genetic: mutations to streptomycin resistance or dependence are allelic and result in demonstrable changes in the ribosome. According to the Spotts \& Stanier hypothesis, the development of resistance to streptomycin is explained by the loss of affinity of the ribosomes in the resistant cells for the streptomycin molecule. Our results support the above ideas. Since genetic mapping of the str locus in pneumococcus has shown that mutations to different levels of streptomycin resistance in this organism arise within a single locus, and since the ribosomes are demonstrably changed when such mutations occur, it seems clear that the str locus of pneumococcus must carry the information for the synthesis of a ribosomal component. Whether this component is RNA or protein is not known with certainty. However, Leboy, Cox \& Flaks (I964) have reported that the locus governing the synthesis of a certain ribosomal protein in Escherichia coli $\mathrm{K} \mathrm{I} 2$ maps close to or is identical with the streptomycin locus. Their finding offers some support for the idea that the ribosomal component involved in streptomycin resistance is a protein.

Our experiments show, moreover, that there is a good correspondence between the in vivo resistance of ribosomes to streptomycin-caused inhibition and misreading and the in vivo resistance of the pneumococcal cells from which the ribosomes were derived. The widely different levels of resistance which occur in our strains can be explained by the idea that mutation-caused changes in the ribosome result in changes in the magnitude of the constant for ribosome-to-streptomycin binding. This idea implies that it is ribosomally bound streptomycin which causes interference with cell multiplication and cell death. Just how ribosomally bound streptomycin kills the cell is not clear. The exciting discovery of Gorini \& Kataja (I964) and of Davies et al. (1964) that streptomycin causes misreading of mRNA in vivo and in vitro led for a time to the idea that streptomycin kills the cell by causing the formation of nonfunctional proteins. Later work (Freda \& Cohen, I966a, $b$; Stern, Barner \& Cohen, 1966) has indicated that the misreading effect of streptomycin alone may not be able to account for cell death. The present state of knowledge about misreading has been reviewed by Gorini (1967). 
There is evidence from Cohen's laboratory (Freda \& Cohen, I966b) that streptomycin killing is associated with an increase in ribosomal RNA synthesis. Cohen et al. (I967) have recently proposed that polycationic streptomycin may kill the cell by crosslinking the ribosome-DNA-RNA complex involved in co-ordinate transcriptiontranslation. Our results are not inconsistent with this suggestion provided one postulates that it is the ribosome which dictates whether or not streptomycin can bind to the ribosome-RNA-DNA complex.

One of the authors (J.J.S.) was a U.S. Public Health Service pre-doctoral trainee. This investigation was supported by U.S.P.H.S. Training Grant 5T I GM 137-09 and by Grant GB-3I36 to A. W.R. from the National Science Foundation.

The support and encouragement of Dr Elmer H. Stotz and the advice of Dr Alexander J. Dounce and of Dr Minna B. Rotheim are gratefully acknowledged. We also thank Dr Luigi Gorini for his helpful comments.

\section{REFERENCES}

Cohen, S. S., Hoffner, N., Jansen, M., Moore, M. \& Raina, A. (1967). Polyamines, RNA synthesis, and streptomycin lethality in a relaxed mutant of E. coli strain I5 TAU. Proc. natn. Acad. Sci. U.S.A. 57,721 .

DAVIES, J. E. (1964). Studies on the ribosomes of streptomycin-sensitive and resistant strains of Escherichia coli. Proc. natn. Acad. Sci. U.S.A. 51, 659.

Davies, J., Gilbert, W. \& Gorini, L. (1964). Streptomycin, suppression, and the code. Proc. natn. Acad. Sci. U.S.A. 5r, 883.

Davies, J., Gorini, L. \& Davis, B. D. (1965). Misreading of RNA codewords induced by amino glycoside antibiotics. Molec. Pharmacol. r, 93.

Davies, J., Jones, D. S. \& Khorana, H. G. (1966). A further study of mis-reading of codons induced by streptomycin and neomycin using ribopolynucleotides containing two nucleotides in alternating sequence as templates. J. molec. Biol. $\mathbf{1 8}, 48$.

EPHRUSSI-TAYLOR, H. E. (I95I). Transformations allogènes du pneumocoque. Expl Cell Res. 2, 589.

Flaks, J. G., Cox, E. C., Wirting, M. L. \& White, J. R. (1962). Polypeptide synthesis with ribosomes from streptomycin-resistant and dependent E. coli. Biochem. biophys. Res. Commun. 7, 390.

Freda, C. E. \& Cohen, S. S. (1966a). Streptomycin and infection of Escherichia coli by T6r+ bacteriophage. J. Bact. 92, I670.

FredA, C. E. \& Cohen, S. S. (I966 b). Nature of ribonucleic acid stimulated by streptomycin in the absence of protein synthesis. J. Bact. $\mathbf{9 2}, \mathbf{1 6 8 0}$.

GorinI, L. (1967). Induction of code ambiguity by aminoglycoside antibiotics. Fedn Proc. Fedn. Am. Socs exp. Biol. 26, 5.

Gorini, L. \& Kataja, E. (1964). Phenotypic repair by streptomycin of defective genotypes in E. coli. Proc. natn. Acad. Sci. U.S.A. 5I, 487.

HANSEN, D. L. \& BuSh, E. T. (I967). Improved solubilization procedure for liquid scintillation counting of biological materials. Analyt. Biochem. 18, 320.

KaJI, A., KAJI, H. \& Novelli, G. D. (I965). Soluble amino acid-incorporating system. I. Preparation of the system and nature of the reaction. J. biol. Chem. 240, 1185.

van Knippenberg, P. H., van Ravensway Classen, J. C., Grijm-Vos, M., Veldstra, H. \& Bosch, T. (1965). Stimulation and inhibition of polypeptide synthesis by streptomycin in ribosomal systems of Escherichia coli, programmed with various messengers. Biochim. biophys. Acta 95, 46I.

Leboy, P. S., Cox, E. C. \& FlaKs, J. G. (1964). The chromosomal site specifying a ribosomal protein in Escherichia coli. Proc. natn. Acad. Sci. U.S.A. 52, 1367.

Lowry, O. H., Rosebrough, N. J., FARr, A. L. \& RandalL, R. J. (1956). Protein measurement with the Folin phenol reagent. J. biol. Chem. 193, 265.

Matthaei, J. H. \& NiRenberg, M. W. (1961). Characteristics and stabilization of DNAase-sensitive protein synthesis in E. coli extracts. Proc. natn. Acad. Sci. U.S.A. 47, I580. 
Mishra, A. K. \& Ravin, A. W. (1966). Genetic linkage of streptomycin-dependence and resistance in pneumococcus. Genetics 53, I 197.

NewCombe, H. B. \& NyноLм, M. H. (1950). The inheritance of streptomycin resistance and dependence in crosses of Escherichia coli. Genetics 35, 603.

NirenberG, M. W. \& MatThaei, J. H. (1961). The dependence of cell-free protein synthesis in E. coli upon naturally occurring or synthetic polyribonucleotides. Proc. natn. Acad. Sci. U.S.A. 47, I588.

RosenKRANZ, H. R. (1964). Basis of streptomycin resistance in Escherichia coli with a multiple drug resistance episome. Biochim. biophys. Acta 8o, 342.

Rotheim, M. B. \& RAVIN, A. W. (196I). The mapping of loci affecting streptomycin resistance in pneumococcus. Genetics 46, I6I9.

Rotheim, M. B. \& RAvin, A. W. (I964). Sites of breakage in the DNA molecule as determined by recombination analysis of streptomycin-resistance mutations in pneumococcus. Proc. natn. Acad. Sci. U.S.A. 52, 30.

SawAda, F. \& SUzuki, K. (1964). Streptomycin-sensitive and resistant ribosomes of Diplococcus pneumoniae. Biochim. biophys. Acta 80, 160.

SchwarTZ, J. H. (1965). An effect of streptomycin on the biosynthesis of the coat protein of coliphage $\mathrm{f} 2$ by extracts of E. coli. Proc. natn. Acad. Sci. U.S.A. 53, I 133.

So, A. G., Bodley, J. W. \& DaviE, E. W. (1964). The influence of environment on the specificity of polynucleotide-dependent amino acid incorporation into polypeptide. Biochemistry 3, 1977.

SPEYER, J. F., Lengyel, P. \& BAsILIO, C. (I962). Ribosomal localization of streptomycin sensitivity. Proc. natn. Acad. Sci. U.S.A. 48, 684.

SPOTTS, C. R. \& STANIER, R. Y. (I96I). Mechanism of streptomycin action on bacteria: a unitary hypothesis. Nature, Lond. 192, 633.

Stern, J. L., BARNeR, H. D. \& CoHEN, S. S. (I966). The lethality of streptomycin and the stimulation of RNA synthesis in the absence of protein synthesis. J. molec. Biol. 17, I88.

SZER, W. \& OCHOA, S. (1964). Complexing ability and coding properties of synthetic polynucleotides. J. molec. Biol. 8, 823 . 